\title{
Much Ado About Disney?
}

\author{
Tereza Zálešáková
}

George Rodosthenous (ed.). The Disney musical on stage and screen: critical approaches from 'Snow
White' to 'Frozen'. New York: Bloomsbury Methuen Drama, 2017. $268 \mathrm{pp}$.

The Disney Musical on Stage and Screen is not the first book on Disney's musicals; nevertheless, it is probably the first collection of critical approaches to Disney's musicals in such a wide range. Moreover, it is the very first publication on Disney musicals which is taken into consideration in the field of Czech theatre studies.

The Disney Musical on Stage and Screen: Critical Approaches from 'Snow White' to 'Frozen' consists of thirteen chapters which are split into three sections: Disney $\mathrm{Mu}-$ sicals: On Film, Disney Adaptations: On Stage and Beyond, and Disney Musicals: Gender and Race. However, this distribution is only formal because regardless of the way of adaptation (for stage or screen) the main topics highlighted by the editor George Rodosthenous emerge in all these chapters.

In a short introduction, Rodosthenous establishes three main frameworks or perspectives for considering the Disney musical presentation. They 'revisit musicals not only as popular entertainment or as a globalized commercial product, but firstly as a political tool for enhancing our understanding of race, sexuality, and gender, secondly as an educational tool for younger children and thirdly as a place for artistic innovation' (2). This volume presents the Disney brand as a pioneering and innovative, philanthropic and educational tool as well as non-original, limited, homophobic, racially incorrect and even misogynist 'author' whom it is necessary to challenge, while at the same time being aware of the fact that Disney represents something very inherent to the formation of American society.

In the first section, there are primarily chapters which focus on musical dramaturgy of both Disney's classics and new productions. Raymond Knapp's chapter is based on the comparison of Tchaikovsky's ballet score of The Sleeping Beauty (1899) and the Disney version (1959). The article itself provides a highly sophisticated musicological analysis of this 'relationship' - an analysis of the music and songs in Disney's movie and how this derived score and songs usage generate an internal logic and secures a narrative line of the piece. Interestingly, it would be challenging to discuss such 'borrowing' of themes and motifs in musicals because other chapters of the book remind the reader of similar topic derivations (e.g., The Lion King); however, Knapp does not mention this issue.

In this volume, there are also several chapters, especially in the second section, which might be more of interest for the non-Anglo-American readers either because of their recent worldwide impact or the closer geographical area of their production. For instance, Olaf Jubin's contribution to a process of 'Disneyfication' of Victor Hugo's novel character Quasimodo 
draws attention from Broadway and the West End to the German productions of Disney's stage musicals.

It is remarkable to observe several practices of the Disney Theatrical Group (DTG) emerging throughout the volume. The first instance might be how DTG cares about localizing every show they stage outside Broadway in order to be more 'tailored' for a local audience even if it is a 'replica'. This is followed by how thoroughly DTG pays attention to research and development to ensure the success of their international stage outcomes, and finally, how this fits into a precisely working machine of this giant corporation (including not only musicals, but also amusement parks, merchandising, licensing shows for schools and more) in order to make a profit.

On this account, the chapter by Stacy E. Wolf called 'Not only on Broadway: Disney JR. and Disney KIDS Across the USA' seems to be very handy to a non-American reader. Wolf here illuminates a supportive and educational role of DTG's programme 'Disney Musicals in Schools' for public schools, which enables underprivileged children to participate in school art programmes. Though it is questionable in terms of side effects and benefits of this project to Disney advertisement and profit, this could be seen at least as noteworthy evidence of persistent (even though slightly modified) American dream - 'everybody can be a Disney producer'.

One of the topics emerging throughout the volume is the impact of the traditional Disney princess stereotype and its recent re-imagination in several recent musicals (i.e. Enchanted, High School Musical, Frozen). This means, after all, that nowadays there are some attempts in musicals to break through Disney's narrative and the depiction of the stereotypes forged in Snow White (1937).

Specifically, in a chapter on High School Musical a live-action film musical, Dominic Symonds points out the stereotypical portraying of gender role distribution in the high school environment as well as the existence of a new post-feminism girl role model which is challenging the Disney princess stereotype in live-action film musicals. Interestingly, it seems more important to emphasise the contradiction of the persistent stereotypical depiction of the high school teenager community as on the one hand strictly differentiated and on the other hand as a warmly open inclusive society.

Study on Enchanted (2007) by Paul R. Laird demonstrates the self-reflexivity of Disney creators while revealing what happens when typical Disney tropes enter the real world.

A culmination of this topic can be seen in the last chapter dedicated to Disney's recent the animated blockbuster Frozen, in which Sarah Whitfield considers this movie as a particular melting point of Disney's stereotypes including gender and queer until-now-limited point of view.

The third part: 'Disney Musicals: Gender and Race', where Frozen is placed, provides a fairly sharp investigation of gender, queer and race issues. Sam Baltimore investigates orientalism intertwined with queerness in Aladdin, and at the end of the essay, he delineates the shift in interpretation of the role of the Genie performed by Tony Award winner James Monroe Iglehart. A climax of the 'race line' is condensed in a paper on The Jungle Book stage version written by the quartet of authors Emily Clark, Donatella Galella, Stefanie A. Jones, and Catherine Young. 
Probably, the latter is the most challenging for the central European point of view. Of course, there is a different level of sensitivity to these issues, concerning not only race. It is easy to imagine Mowgli as a girl, at the same time, why should it be necessary to portray Simba (The Lion King) as a female character if there is gender balance sustained by the re-empowerment of women position in portraying Rafiki as a woman in the stage version? It is evident that this discrepancy is caused by the observer's very own point of view as one can see the reviewer's discussion whether Frozen is too or not enough feminist.

Even though this approach is offered by scholars and academics, from time to time, there is a noticeable tendency of both slightly enthusiastic reading of Disney's output and harsh critique of Disney's practice.

From our point of view, it may seem to be unnecessary to bring something so fundamentally related to American (or Anglo-American) society and culture into the context of Czech theatre studies. Notwithstanding, there is a visible overlap of Czech popular culture and the Disney brand. On the one hand, as can be seen in the repertoire of Czech theaters, there are no blockbuster stagings or tours across the Czech Republic as there are in Germany, but some Czech musical theatres know how to exploit Disney's musicals that are more suitable for its mode of the non-serial staging. On the other hand, there is an undeniable repercussion of both recent animated and live-action film musicals (e.g. High School Musical). It could be interesting to investigate the degree of 'Disneyization' of Czech society.

Regardless of how questionable the book might seem, it is worth reading. Theatre, and musical theatre especially, due to its position between stage and screen and its popular status worldwide, is not only a dramatic structure, synthesis of elements and an interpretation of the creator's intentions. It is also a mirror of society as a whole and the individual consumer who is a part of it.

Thus, based on these observations of academics and scholars worldwide trying (by using more or less questionable approach) to unlock this 'Pandora's box', it might be an encouragement for the beginning of taking our own 'giants' into consideration. 